\title{
Acrylamide formation in vegetable oils and animal fats during heat treatment
}

\begin{abstract}
The method of liquid chromatographic tandem mass spectrometry was utilized and modified to confirm and quantify acrylamide in heating cooking oil and animal fat. Heating asparagine with various cooking oils and animal fat at $180{ }^{\circ} \mathrm{C}$ produced varying amounts of acrylamide. The acrylamide in the different cooking oils and animal fat using a constant amount of asparagine was measured. Cooking oils were also examined for peroxide, anisidine and iodine values (or oxidation values). A direct correlation was observed between oxidation values and acrylamide formation in different cooking oils. Significantly less acrylamide was produced in saturated animal fat than in unsaturated cooking oil, with $366 \mathrm{ng} / \mathrm{g}$ in lard and $211 \mathrm{ng} / \mathrm{g}$ in ghee versus $2447 \mathrm{ng} / \mathrm{g}$ in soy oil, followed by palm olein with $1442 \mathrm{ng} / \mathrm{g}$.
\end{abstract}

Keyword: Acrylamide; Animal fats; LC-MS/MS; Oxidation values; Vegetable oils 